\title{
HRS Policy Statement: Clinical Cardiac Electrophysiology Fellowship Curriculum: Update 2011
}

\author{
Mark S. Link, MD, FACC, FHRS ${ }^{1}$ [Chair], Derek V. Exner, MD, MPH, FHRS ${ }^{2}$, Mark Anderson, \\ MD, PhD ${ }^{3}$, Michael Ackerman, MD, PhD ${ }^{4}$, Amin Al-Ahmad, MD, FHRS ${ }^{5}$, Bradley P. Knight, \\ MD, FHRS ${ }^{6}$, Steven M. Markowitz, MD ${ }^{7}$, Elizabeth S. Kaufman, MD, FHRS ${ }^{8}$, David Haines, \\ MD, FACC, FHRS $^{9}$, Samuel J. Asirvatham, MD ${ }^{10}$, David J. Callans, MD ${ }^{11}$, J. Paul Mounsey, \\ BM BCh, PhD ${ }^{12}$, Frank Bogun, MD ${ }^{13}$, Sanjiv M. Narayan, MD, PhD, FHRS ${ }^{14}$, Andrew D. \\ Krahn, MD FHRS ${ }^{15}$, Suneet Mittal, MD, FACC, FHRS ${ }^{16}$, Jagmeet Singh, MD, PhD ${ }^{17}$, John D. \\ Fisher, MD, FHRS ${ }^{18}$, and Sumeet S. Chugh, MD, FHRS ${ }^{19}$ \\ ${ }^{1}$ Tufts Medical Center, Boston, Massachusetts, University of Calgary, Alberta, Canada \\ ${ }^{2}$ Libin Cardiovascular Institute of Alberta, University of Calgary, Alberta, Canada \\ ${ }^{3}$ University of lowa, lowa City, lowa \\ ${ }^{4}$ Mayo Clinic, Rochester, Minnesota \\ ${ }^{5}$ Stanford University Medical Center, Stanford, California \\ ${ }^{6}$ Northwestern University, Evanston, Illinois \\ ${ }^{7}$ Weill Cornell Medical College, New York, New York \\ ${ }^{8}$ Heart \& Vascular Center, MetroHealth Campus, Case Western Reserve University, Cleveland, \\ Ohio \\ ${ }^{9}$ Oakland University William Beaumont School of Medicine Beaumont Hospitals, Rochester, \\ Michigan \\ ${ }^{10}$ Mayo Clinic, Rochester, Minnesota \\ ${ }^{11}$ University of Pennsylvania, Philadelphia, Pennsylvania \\ ${ }^{12}$ University of North Carolina, Chapel Hill, North Carolina \\ ${ }^{13}$ University of Michigan, Ann Arbor, Michigan \\ ${ }^{14}$ University of California and VA Medical Center at San Diego, San Diego, California \\ ${ }^{15}$ University of Western Ontario, Ontario, Canada \\ ${ }^{16}$ The St. Luke's and Roosevelt Hospitals Center, New York, New York \\ ${ }^{17}$ Massachusetts General Hospital, Boston, Massachusetts \\ ${ }^{18}$ Montefiore Medical Center, Albert Einstein College of Medicine, Bronx, New York
}

(C) 2011 Heart Rhythm Society. All rights reserved.

Correspondence and reprint requests: Sonja Olson, Heart Rhythm Society, 1400 K Street NW, Suite 500, Washington, DC, 20005. solson@hrsonline.org. 


\section{Introduction}

A fellowship curriculum is important in the training of a clinical cardiac electrophysiologist. A clinical cardiac electrophysiology curriculum was first published in 2001 and was the basis for education in many fellowship programs. ${ }^{1}$ Over the last 10 years cardiac electrophysiology has continued to grow, evolve, and mature so that an update is currently needed. This update is focused on what a practicing electrophysiologist will need in the care of patient. It is not meant to be a mandatory education requirement or to supplant American Board of Internal Medicine (ABIM) or Accreditation Council for Graduate Medical Education (ACGME) requirements. Each section was written by one of the authors, but all authors have reviewed the entire document.

\section{Normal physiology}

Fellows should possess an understanding of the basic anatomic, cellular and molecular mechanisms of electrophysiology as they pertain to normal physiology. These concepts include the cellular and molecular bases for electrical function of the heart under normal and pathophysiologic conditions, anatomic relationships within the heart, the mechanisms responsible for the development of arrhythmias, and the actions of antiarrhythmic drugs.

A. Anatomic structures, anatomic relationships and vascular supply ${ }^{2-5}$

1. Conduction system (sinus node, intranodal pathways, AV node, His bundle and bundle branches, and Purkinje fibers)

2. Venous anatomy (superior and inferior vena cava, coronary sinus and its branches, pulmonary veins)

3. Anatomy of great vessels (right and left ventricular outflow tracts) including relationship to aortic sinuses of Valsalva and ostia of coronary arteries

4. Autonomic nervous system, ganglionic plexi, and phrenic nerve

B. Resting membrane potential, action potential and passive membrane properties $^{2,6-10}$

1. Genesis of the resting potential in excitable cells

2. Active membrane properties

3. Cardiac action potentials (SA node, internodal tracts, atrial myocardium, AV node, bundle of His, bundle branches, Purkinje fibers, ventricular muscle)

4. Passive membrane properties

5. Channels and ionic currents responsible for the action potential (voltage operated, pump and exchange currents, ligand operated, mechanosensitive) 
6. Genes encoding for cardiac ion channels, exchangers, and pumps

7. Electrical heterogeneity

8. Mechanisms of automaticity in nodal and Purkinje pacemakers

9. Impact of drugs

C. Determinants of normal conduction ${ }^{2}$

1. Structure and function of gap junctions

2. Passive membrane properties and electrotonic interactions

3. Anisotropy

4. Modulation of these factors by sympathetic and parasympathetic agonists

5. Excitability, supernormality and vulnerability

D. Cellular basis for the inscription of the $\mathrm{ECG}^{11,12}$

1. P wave

2. QRS

3. T wave and ST segment

4. J wave

5. U wave

E. Ion channels

1. Voltage-gated ion channels ${ }^{13}$

2. Ligand operated ion channels (include RyR) ${ }^{14,15}$

3. Connexins ${ }^{16}$

4. Regulation of ion channels in health and disease ${ }^{17,18}$

5. Ion channels as targets for genetic arrhythmia syndromes

6. Ion channels as anti- and pro-arrhythmic drug targets ${ }^{19,20}$

\section{Genetic basis of arrhythmia}

The heritable arrhythmia syndromes, also known collectively as the cardiac channelopathies, represent an exciting and expanding discipline for electrophysiologists. ${ }^{21}$ Since heart rhythm specialists are typically the primary caretakers for patients with heritable arrhythmia syndromes and their families, the fellow needs to be familiar with the following:

A. The spectrum of heritable arrhythmia syndromes/cardiac channelopathies including 22 :

1. Long QT syndrome (LQTS)

2. Brugada syndrome $(\mathrm{BrS})$

3. Catecholaminergic polymorphic ventricular tachycardia (CPVT)

Heart Rhythm. Author manuscript; available in PMC 2014 June 27. 
4. Short QT syndrome (SQTS)

5. Progressive cardiac conduction disease (PCCD)

6. Familial atrial fibrillation (FAF)

7. Inferolateral early repolarization syndrome

8. Commotio cordis ${ }^{23}$

B. The pathogenetic basis for the cardiac channelopathies including 22,24 :

1. Loss-of-function mutations in potassium channels (Kv7.1 and Kv11.1) explaining two-thirds of all LQTS

2. Loss-of-function mutations in the sodium channel (Nav1.5) explaining $\sim 25 \%$ of $\mathrm{BrS}$ with the majority of $\mathrm{BrS}$ still being genetically elusive

3. Mutations in the RYR2-encoded cardiac ryanodine receptor as the cause for approximately two-thirds of CPVT

C. Genotype-phenotype relationships and risk stratification for each channelopathy $7,22,24,25$

D. The state of genetic testing for each cardiac channelopathy including $26-28$ :

1. Diagnostic, prognostic, and therapeutic implications

2. The yield of genetic testing

3. Distinguishing true pathogenic mutations from background genetic noise

4. The need for pre-genetic test counseling and acquisition of those skills or partnership with genetic counselors and/or geneticists

E. The indications for pharmacotherapy, left cardiac sympathetic denervation therapy, and device therapy for the cardiac channelopathies $7,24,25$

\section{Diagnosis of arrhythmia}

\section{1: Surface ECG and ambulatory monitoring}

Clinical Cardiac Electrophysiology Fellows should meet minimum competency requirements of Cardiovascular Disease fellowship training for electrocardiogram (ECG) interpretation as outlined by the American College of Cardiology Task Force. Fellows are expected to be fully familiar with the indications and performance of a variety of noninvasive ECG tests.

A. Surface ECG interpretation ${ }^{2,29-31}$

1. Evaluation of normal and abnormal intervals

2. Recognition of myocardial infarction and evidence of ischemia

3. Metabolic/drug effects with special attention to antiarrhythmic toxicity (QT prolongation and conduction abnormalities)

4. Classification and mechanism of conduction disturbances and block 
5. Chamber hypertrophy or enlargement; ECG findings in athletes

6. Atrial and ventricular paced rhythm with recognition of:

- Site of pacing

- Failure of appropriate pacemaker function

- Mode of pacing; presence of biventricular pacing

7. Identification of accessory AV connection location, ventricular tachycardia, atrial tachycardia location

8. Recognition of ECGs associated with clinical syndromes (long QT, short QT, Brugada, ARVC/D, secundum ASD, Wolff-Parkinson-White, HCM, myotonic dystrophy type I)

9. Fusion and capture beats

10. Identification of technical problems such as misplaced leads and artifact

B. Noninvasive ECG tests ${ }^{32-34}$

1. Ambulatory ECG recordings

2. Continuous on-line ECG monitoring (telemetry)

3. Mobile outpatient ECG monitoring with telephone-based telemetry

4. Identification of artifact, distinguishing artifact from arrhythmias

5. Manually and automatically activated event/loop/mobile cardiac outpatient telemetry (MCOT) recorders with an understanding of the use of each

6. Analysis of signal-averaged ECGs

7. Exercise testing for the presence of myocardial ischemia and/or arrhythmias; assessment of appropriate shortening of QT

8. Heart rate variability, heart rate turbulence and other ambulatory ECG measures of autonomic balance as risk markers

9. T wave alternans as a risk stratifier

10. Indication for implantable loop recorders

C. Bradyarrhythmias

1. Abnormalities of sinus node function, including inappropriate sinus bradycardia, sinus arrest, and sinus exit block

2. Abnormalities of $A V$ conduction and their localization to the AV node, His bundle, or His-Purkinje system

D. Tachyarrhythmias ${ }^{35-40}$

1. Recognition of atrial tachycardia, reentrant arrhythmias using manifest or concealed AV connection pathways, and AV nodal reentrant tachycardias (AVNRT) 
2. Localization of atrial tachycardia

3. Typical and reverse typical (isthmus dependent) atrial flutter, lesion reentry, left atrial, and atypical flutters

4. Localization of re-entry in atypical flutter

5. Atrial fibrillation with particular reference to focal origins

6. Wide QRS complex tachycardia with special attention paid to distinguishing VT from supraventricular tachycardia with aberrant ventricular conduction and ventricular preexcited tachycardias

7. Special ventricular arrhythmias include:

- Ventricular ectopy with special attention to bigeminy and parasystole as well as the quantification of beats over a 24hour period. Localization of ventricular ectopic beats within the right and left ventricles, aortic cusp and epicardial surface

- Nonsustained VT (monomorphic or polymorphic) with or without associated long QT intervals

- Sustained VT with particular attention to idiopathic VT versus tachycardia associated with organic heart disease

- Sustained polymorphic VT with or without long QT intervals

- Bidirectional VT and other drug-induced tachycardias

E. Miscellaneous arrhythmogenic situation $30,31,39-41$

1. LQTS; specific patterns of $T$ waves related to gene defect

2. Brugada syndrome ${ }^{24}$

3. Arrhythmogenic right ventricular dysplasia ${ }^{30}$

4. Idiopathic ventricular fibrillation

- $\quad$ Short QT syndrome

- $\quad$ Early repolarization patterns ${ }^{40}$

5. Commotio cordis ${ }^{41,42}$

\section{2: Invasive electrophysiological evaluation}

Electrophysiology fellows should be able to list the indications for invasive electrophysiologic studies; perform and interpret a comprehensive electrophysiologic study; create and interpret an electroanatomic endocardial activation map; indicate the sensitivity and specificity of these findings; integrate these findings into the clinical care of the patient, use the information to formulate an ablation strategy when indicated.

A. Principles of multi-electrode catheter placement, electrogram recording, and stimulation 
1. Techniques of intracardiac, multielectrode catheter placement in rightsided chambers, and in left-sided chambers using coronary sinus, transseptal, and retrograde aortic approaches

2. Genesis of the intracardiac recording

3. Types of recordings

- Unipolar

- Bipolar

- $\quad$ Effect of electrode spacing

- $\quad$ Effect of electrode orientation (linear, orthogonal)

4. Filtering

- Bandpass and its effect on signal content

- Notch filter

5. Gain and clipping of recorded signal

6. Electrode field and concept of local activation time

7. Display of electrograms using a basic electronic electrophysiology recording system. Understanding electrical connections and troubleshooting of such systems

8. Principles of advanced three-dimensional mapping systems including anatomical chamber reconstruction, image integration, and creation and interpretation of electroanatomical and voltage maps ${ }^{43}$

9. Principles of stimulation

- Concept of pacing threshold

- Types of stimulation and implications for pace mapping

- Unipolar

- $\quad$ Bipolar

B. Sinus node, AV node and His-Purkinje system function ${ }^{44-46}$

1. Obtaining and evaluating the sinus node recovery time, and sinoatrial conduction time

2. Intra-atrial versus $A V$ nodal conduction disease

3. AV nodal function and dysfunction in response to atrial pacing

4. Diagnose conduction delay or block as within the AV node or His-

Purkinje system, and integrate this information with regard to need for permanent cardiac pacing 46

C. Supraventricular tachycardias (SVTs) 
1. Understand mechanisms and methods of induction of different SVTs

- Atrial fibrillation

- Atrial tachycardia and flutter

- Focal

- $\quad$ Macroreentrant

- $\quad$ Post left atrial ablation for atrial fibrillation

- AV node reentrant tachycardia

- AV reentrant tachycardia

- Junctional ectopic tachycardia

2. Use of baseline observations, tachycardia features, and pacing maneuvers to differentiate various forms of $\mathrm{SVT}^{47}$

D. Ventricular arrhythmias

1. Detail the number of sites and standard stimulation protocol for induction of VT

2. Recognize the value of His-bundle and atrial recordings in the diagnosis of $\mathrm{VT}$ and/or bundle branch reentry

3. Detail the sensitivity, specificity, and efficiency of induction protocols with respect to clinical presentation (VT, sustained and nonsustained, or ventricular fibrillation) and underlying myocardial substrate ${ }^{48}$

E. Principles of resetting and entrainment and termination of tachycardias ${ }^{49-51}$

1. Interpretation of resetting curves

2. Definition of entrainment

- Constant fusion during pacing at a constant rate faster than the tachycardia except for the last captured beat that is not fused

- Progressive fusion

- Interruption of tachycardia by overdrive pacing associated with localized conduction block to a site followed by activation of that site by the next pacing impulse from a different direction and with a shorter conduction time

- Change in conduction time and electrogram morphology at one recording site when pacing from another site at two different constant pacing rates, each of which is faster than the spontaneous rate of the tachycardia, but fails to interrupt it (electrogram equivalent of progressive fusion) 
3. Techniques of entrainment

- Pacing technique and assurance of capture

- Types of ECG/intracardiac fusion and their implications

- $\quad$ Fixed fusion

- $\quad$ Progressive fusion

- $\quad$ Concealed entrainment

4. Implications of entrainment

- Presence of reentry

- $\quad$ Significance for mapping

5. Recognition of termination without global capture

6. Identification of reentry circuit sites during catheter mapping and radiofrequency ablation of ventricular tachycardia late after myocardial infarction.

\section{3: Laboratory safety}

Electrophysiology trainees should understand principles of laboratory safety, with regard to maximizing protection of patients, operators, and laboratory staff. Emphasis should be placed on educating trainees in the use and effects of diagnostic radiation. Other categories of laboratory safety include proper use of electrosurgical instruments, and prevention of transmissible diseases.

A. Use and effects of ionizing radiation ${ }^{52}$

1. Principles of $X$-ray imaging

- Units and measurements of ionizing radiation

- Operation of X-ray equipment

- Procedures and X-ray settings for image acquisition

- Methods for dose reduction

2. Risks of X-ray imaging for patients

- Deterministic effects of X-rays (skin injury)

- Stochastic effects of X-rays (neoplasm)

- Follow-up of patients exposed to diagnostic radiation

- Managing X-ray exposure for pregnant patients

3. Risks of X-ray imaging for operators and staff

- X-ray protection protocols and techniques

- Monitoring of occupational radiation exposure and regulatory limits 
- Precautions for medical employees during pregnancy

B. Safe use of electrosurgery in the electrophysiology laboratory

1. Electrosurgery in operative procedures

- Biological effects of electrosurgical waveforms

- Potential harm of electrosurgery - Tissue necrosis

- $\quad$ Improper grounding

- $\quad$ Interaction with operative environment and protection of operative field

(flammable gasses)

- Interaction with implantable cardiac rhythm devices

2. Radiofrequency in catheter procedures ${ }^{53}$

- Biophysics of catheter ablation

- Factors affecting lesion formation

- Methods of delivering intracardiac radiofrequency energy (solid electrode, irrigated, hybrid bipolar and unipolar)

- Risks of intracardiac radiofrequency energy (perforation, thrombosis, volume overload)

- Risks of improper grounding pad placement

C. Precautions for transmissible diseases

1. Transmissible agents in invasive procedures (hepatitis B, hepatitis $\mathrm{C}, \mathrm{HIV}$ )

2. Modes of transmission (injection, splash)

3. Risks of infection with different agents

4. Prophylaxis of infection among operators

- Precautions

- Post-exposure prophylaxis

\section{Treatment of arrhythmia}

\section{1: Basic pharmacokinetics and pharmacodynamics}

Pharmacokinetics and pharmacodynamics are essential concepts in understanding therapeutic drug delivery. Although drugs are less commonly used clinically as a first-line therapy for ventricular arrhythmias, they frequently are utilized as adjunctive therapy. In addition, antiarrhythmic agents are frequently used for management of atrial fibrillation.

A. Basic pharmacokinetic principles ${ }^{54,55}$

1. Absorption 
2. Distribution, especially effect of heart failure and shock on central volume of distribution

3. Metabolism, especially role of cytochrome $\mathrm{P} 450$ system and of pglycoprotein;

4. Positive and negative effects on these metabolic systems by other drugs, diet, genetic variants

5. Elimination of drugs by liver, kidney, and lungs

B. Clinical pharmacokinetics

1. Drug interactions

2. Effect of age, gender, disease states

C. Pharmacodynamics

1. How drugs affect the body via receptors

2. Agonists and antagonists

D. Pharmacodynamics and pharmacokinetics of antiarrhythmic drugs

1. Utility and limitations of various classification schemes: VaughanWilliams, Sicilian Gambit, etc.

2. Effects of drugs on ion channels

3. Effects on conduction and refractoriness of atrial and ventricular myocardium, bypass tracts, and His-Purkinje tissue

4. The following information for individual antiarrhythmic agents in normal subjects and in patients with renal, hepatic, or heart failure or with hypertrophy or abnormal repolarization:

- Indications

- Contraindications

- Dosages

- Drug interactions

- Diagnosis and management of adverse effects ${ }^{10}$

- Pathways for metabolism and elimination

5. Range of expected elimination $t 1 / 2$

Use dependence and reverse use dependence

E. Individual antiarrhythmic medications ${ }^{56,57}$

1. Class 1a: Quinidine, Disopyramide, Procainamide

2. Class 1b: Mexiletine

3. Class 1c: Flecainide, Propafenone

Heart Rhythm. Author manuscript; available in PMC 2014 June 27. 
4. Class III: Sotalol, Dofetilide, Amiodarone, Dronedarone, Ibutilide

5. Adenosine

6. Ranolazine

F. Drug-device interactions

1. Effect on pacing threshold and defibrillation efficacy

2. Effect on tachycardia cycle length and response to antitachycardia pacing

\section{2: New technology/ablation physics}

It is useful for fellows to understand the scientific basis of lesion formation during catheter ablation. One should know the factors that affect the successful application of an ablative lesion and learn how to modify those factors to yield safe and effective catheter ablations.

\subsection{1: Biophysics of ablation-}

A. Modes of tissue heating $53,58-61$

1. Electromagnetic spectrum

- Radiofrequency energy - resistive heating

- Microwave energy - dielectric heating

- Laser energy - photonic heating

- Direct (volume) heating of tissue

- Conductive heating to deeper tissue layers

2. Ultrasound ablation

- Mechanical heating of tissue

- Deep volume heating

3. Direct thermal ablation

4. No volume heating - highest temperature is at source

5. Conductive heating only

B. Factors that increase depth of tissue heating

1. Temperature of source

- Surface temperature limited to $100^{\circ} \mathrm{C}$ because of boiling and coagulum formation

2. Power

3. Size of heat source

4. Duration of heating

C. Convective cooling

Heart Rhythm. Author manuscript; available in PMC 2014 June 27. 
1. Passive

2. Active

3. Beneficial effects of surface cooling

4. Balance of cooling versus heating and power delivery

D. Cryothermic ablation ${ }^{61}$

1. Mechanism of refrigerant vaporizing at catheter tip

2. Cryoadhesion and ice ball formation

\subsection{2: Pathophysiology of ablation-}

A. Tissue effects of hyperthermia

1. Microvascular injury

B. Cellular effects of hyperthermia

1. Thermal poration of sarcolemmal membrane

2. Other organelle damage

C. Cellular effects of freezing and thawing

\subsection{3: Technologies to create therapeutic ablative lesions-}

A. Large tip RF electrodes ${ }^{58,62}$

B. Cooled tip RF electrodes

1. Internally-cooled

2. Perfused tip

C. RF array catheters

1. Circular

2. Mesh

D. Force sensing ablation catheter

E. Laser balloon ablation catheter

F. Hot balloon ablation catheter

G. Cryoballoon ablation catheter

\subsection{4: Adjunctive technologies to facilitate catheter ablation-}
A. Electroanatomic mapping systems
B. Intracardiac echocardiography
C. Robotic catheter manipulation 


\section{3: Imaging technology}

Electrophysiology trainees should be aware of cardiac imaging modalities that aid diagnosis of arrhythmia, as well as invasive management. ${ }^{63,64}$ The relevant imaging may be done prior to an invasive procedure (ablation or device implant), online monitoring during the procedure for complication and catheter guidance, as well as risk stratification and selection of the appropriate procedure.

\subsection{1: Intracardiac ultrasound examination ${ }^{65-67}$}
A. Fellows should be familiar with both rotational and linear phased array
B. Guidance for transseptal catheterization
C. Guidance for pulmonary vein isolation
D. Access to cardiac chambers in patients with congenital heart disease
E. Monitoring for complications, including thrombus and cardiac perforation
F. Guidance during papillary muscle VT ablation
G. Guidance during aortic cusp VT Ablation

\subsection{2: Computerized tomography (CT) for heart and pulmonary veins ${ }^{68}$}

A. Use and evaluation for right ventricular dysplasia and structural abnormality in patients with ventricular tachycardia

B. Pre- and post-ablation imaging for pulmonary vein morphology and detection of pulmonary vein stenosis

\subsection{3: Magnetic resonance imaging ${ }^{69-71}$}

A. Delayed gadolinium enhancement in dilated and hypertrophic cardiomyopathy for risk stratification-sudden cardiac death/ventricular arrhythmia

B. Diagnosis of right ventricular dysplasia and other cardiomyopathies

C. MRI evaluation for congenital heart disease to aid catheter navigation and identification of the arrhythmogenic substrate

D. Merging CT data with electrograms and other invasive electrophysiology data

\subsection{4: Imaging to map electrical activation-}
A. Electroanatomic mapping systems
B. Tissue Doppler evaluation

\subsection{5: Ancillary imaging for invasive electrophysiology therapy-}

A. Ventilation perfusion imaging, quantitative and qualitative for detecting pulmonary vein stenosis 
B. Contrast echocardiography and advanced echocardiographic imaging to identify substrate for ventricular arrhythmia

\section{4: Ablation of SVT}

Clinical electrophysiology fellows should understand which patients would be expected to benefit from radiofrequency ablation of SVT. They should be confident in the laboratory differential diagnosis of SVT and the techniques required for ablation. They should have experience in the use of three-dimensional mapping systems, techniques for retrograde and transseptal access, and should understand the underlying anatomy sufficiently to help to avoid complications.

A. Patient selection and pre-procedure evaluation, including cardiac monitoring, exercise stress testing, echocardiography and cardiac catheterization in selected individuals

B. Equipment

1. Catheters types and associated curves

2. Sheaths, including curves and uses

3. Energy sources, including the indications for cryoablation

C. Anatomy ${ }^{72}$

1. Epicardial coronary vessels

2. Atrial anatomy

- AV node and His bundle

- Triangle of Koch

- Subeustachian isthmus

- Crista terminalis

- Pulmonary veins

- Coronary sinus

- Sinus node

- Noncoronary sinus of Valsalva, and significance for atrial ablation

D. Techniques and endpoints

A $\quad$ AVNRT $^{73-77}$

- $\quad$ Types

$$
\begin{array}{ll}
- & \text { Slow/fast } \\
\text { - } & \text { Fast/slow } \\
\text { - } & \text { Slow/slow }
\end{array}
$$


- $\quad$ Other variants

- Ablation of AVNRT

- $\quad$ Slow pathway (preferred method)

- $\quad$ Fast pathway

- Mapping techniques for radiofrequency ablation

- $\quad$ Slow potential guided

- $\quad$ Anatomically guided

- Relative accuracy of endpoints of ablation

- $\quad$ Noninducibility

- Junctional AV beats during ablation

- $\quad$ Elimination of slow pathway

function

2 AV reentrant tachycardia ${ }^{73-75,77,78}$

- Risk stratification in patients with ventricular preexcitation

- $\quad$ Types

- $\quad$ Orthodromic

- $\quad$ Antidromic

- $\quad$ Atypical bypass tracts

- Mapping techniques

- $\quad$ Anterograde activation mapping of the earliest ventricular activity

- Retrograde activation mapping of the earliest atrial activity

- $\quad$ Bypass tract potentials

- $\quad$ Left-sided approaches

- Transseptal

- $\quad$ Transaortic valve retrograde

3 Atrial tachycardia (focal and reentrant) 79,80

- Most frequent sites of origin: Crista terminalis, eustachian ridge, pulmonary veins, valve annuli

- Mapping, including intracardiac pace mapping, threedimensional mapping systems 
- Understanding of influence of prior surgery, atrial fibrosis

- Endpoints

E. Maneuvers to distinguish supraventricular tachycardia mechanism ${ }^{47,81-83}$

1. Classification schemes

- Long RP versus short RP

- Wide QRS complex versus narrow QRS complex

2. Maneuvers

- His refractory ventricular pacing (for narrow complex tachycardia) and atrial pacing (for wide complex tachycardia)

- Changes in tachycardia cycle length and VA time with bundle branch block

- Para-Hisian pacing

- Tachycardia response after burst ventricular pacing

- Tachycardia response after burst atrial pacing (VA linking)

- Ventricular burst pacing during SVT to dissociate the atrium from ventricle

- Evaluation of mode of initiation of SVT (critical AH delay)

F. Complications related to supraventricular tachycardia ablation

- Heart block

- Stroke

- Pericardial tamponade

\section{Atrial fibrillation and flutter}

Heart rate control and rhythm control with drugs remain the mainstay of therapy of atrial fibrillation, however; it has become clear that when drug therapy fails to control symptoms, this goal can be accomplished by ablation. Accumulating evidence that restoration of sinus rhythm by ablation improves symptoms, cardiac function and exercise capacity in selected groups of patients has led to large-scale morbidity and mortality trials, which are ongoing. Even if these trials are ultimately negative, the major symptomatic benefits of restoration of sinus rhythm by ablation suggests that competence endocardial ablation for atrial fibrillation and atrial flutter has become a requirement for graduating EP fellows.

Anticoagulation with vitamin $\mathrm{K}$ antagonists (i.e., warfarin) remains the mainstay of stroke prevention, although left atrial occlusion devices are likely to become clinically available in the lifetime of this document. Most significantly, perhaps, alternatives to anticoagulation with vitamin $\mathrm{K}$ antagonists have been developed, and a prototypical direct thrombin inhibitor, dabigatran, is now approved in the US. Other direct thrombin inhibitors and direct 
factor Xa antagonists are undergoing clinical trials and will likely be clinically available soon.

\section{1: Atrial fibrillation}

A. Mechanisms ${ }^{84-88}$

1. Multiple reentrant wavelets versus single dominant rotor with fibrillatory conduction

2. Pulmonary vein and non-pulmonary vein focal triggers for atrial fibrillation

3. Importance of ganglionated plexi

4. Atrial remodeling

5. The renin-angiotensin-aldosterone system in atrial fibrillation

B. Epidemiology

1. Age associated prevalence - the demographic time bomb

2. Associated co-morbidities: Hypertension, ischemic heart disease, valvular heart disease, congestive car-diac failure, heart surgery, obesity, sleep apnea, other non-cardiac causes

C. Risks of atrial fibrillation ${ }^{87,88}$

1. Stroke and other arterial emboli

2. Tachycardia induced cardiomyopathy

D. Prevention of thromboembolism in atrial fibrillation

1. The trials of vitamin $\mathrm{K}$ antagonists in primary prevention of stroke in atrial fibrillation; meta-analysis of these trials ${ }^{87,88}$

2. The CHADS2 score 87,88

3. Use of aspirin, clopidogrel, and aspirin/clopidogrel combination therapy 89,90

4. Left atrial appendage occlusion devices

5. Direct thrombin inhibitors (e.g., dabigatran) $)^{91,92}$ and factor Xa inhibitors (e.g., Rivaroxaban, apixaban)

E. Drug therapy for atrial fibrillation

1. Strategy selection: Suppression of atrial fibrillation ("rhythm control") versus control of the ventricular response ("rate control"). AFFIRM, RACE, RACE-II and AF-CHF trials ${ }^{93-96}$

2. Selection of heart rate controlling drugs $87,88,96,97$

3. Selection of antiarrhythmic drugs $87,88,97$ 
F. Cardioversion of atrial fibrillation

1. Transthoracic cardioversion

2. Chemical cardioversion, and drug facilitated DC cardioversion

3. Anticoagulation and trans-esophageal echocardiography around cardioversion $^{98}$

G. Nonpharmacologic therapy

1. Device therapy

- Pacing only of benefit in the context of sinus node dysfunction

2. Endocardial catheter ablation ${ }^{99-105}$

- Pulmonary vein isolation: Segmental ostial isolation vs wide area circumferential ablation ${ }^{86}$

- Ablation of complex fractionated atrial electrogram ${ }^{106-109}$

- Linear left atrial

- Ablation of ganglionated plexi ${ }^{110}$

- Isolation of the coronary sinus

- Isolation of the superior vena cava

- Novel ablation modalities: Bipolar radiofrequency ablation, balloon cryoablation

- Pacing maneuvers to differentiate far-field from near-field electrograms

- Pacing maneuvers to evaluate conduction block across left atrial linear lesions

3. Epicardial and surgical treatment

- Cut and sew maze

- Adjunctive atrial fibrillation surgery

- Hybrid endocardial and epicardial atrial fibrillation procedures

4. Indications for $\mathrm{AV}$ junction ablation and pacing

H. Risks of AF ablation

1. Vascular complications

2. Cardiac tamponade

3. Esophageal injury

4. Pulmonary vein stenosis

Heart Rhythm. Author manuscript; available in PMC 2014 June 27. 
5. Phrenic nerve damage

6. Post-ablation atrial tachycardia and flutter

I. Diagnosis, evaluation and management of post-ablation atrial tachycardia

\section{2: Atrial flutter}

A. Classification of atrial flutter

- Classic, cavotricuspid isthmus dependent, atrial flutter - typical (counterclockwise) vs reverse typical (clockwise) ${ }^{111}$

- Scar-mediated atrial flutter

- $\quad$ Post cardiac surgery, especially congenital heart disease $^{112}$

- $\quad$ Post ablation 113

- $\quad$ Atypical (type II) atrial flutter - e.g., upper loop flutter etc.

B. Risks of atrial flutter

- Stroke and other arterial thromboembolism ${ }^{114}$

- Tachycardia-mediated cardiomyopathy

- Association with atrial fibrillation

C. Prevention of thromboembolism in atrial flutter

D. Drug therapy for atrial flutter

- Selection of heart rate controlling drugs

- Selection of antiarrhythmic drugs

E. Nonpharmacologic therapy

- Superiority of catheter ablation over antiarrhythmic drugs in classic atrial flutter ${ }^{115,116}$

- Endocardial catheter ablation ${ }^{117}$

- Importance of bidirectional cavotricuspid isthmus conduction block in long-term success in classic atrial flutter ${ }^{118}$

- Understanding of pseudo-block (slow conduction) and pseudo-conduction (crista breakthrough)

\section{Ablation of VT}

Fellows should recognize the indications, patient selection, risks and anticipated benefits of catheter ablation for ventricular arrhythmias associated with or without structural heart disease. It is reasonable to expect a cure for the majority of patients with truly idiopathic VT, whereas catheter ablation usually is palliative in organic heart disease, especially in advanced ischemic and non-ischemic heart disease. A recent consensus document 
summarizes characteristics of ventricular arrhythmias as well as patient selection for ablation, and ablation results. ${ }^{119}$

1. Idiopathic VT

A. Sites

1. Right ventricular outflow tract and pulmonary artery

2. Left ventricular outflow tract

3. Aortic cusps

4. Mitral and tricuspid annulus

5. Epicardial basal VT

6. Intrafascicular verapamil-sensitive reentrant tachycardia

7. Papillary muscles ${ }^{120}$

B. Mapping techniques ${ }^{121}$

1. Activation mapping and pace-mapping

2. Identification of Purkinje potentials, entrainment mapping

C. Approach: Transvenous right ventricular, retrograde aortic, transseptal, coronary venous system, percutaneous epicardial approach

2. Catheter ablation for non-ischemic cardiomyopathy ${ }^{122,123}$

A. Myocardial VT

1. Mechanism: Reentry within the myocardium

2. Location: Basal left ventricle, epicardium, right ventricle

3. Ablation: Guided by pace-mapping, entrainment mapping, isolated potentials

B. Bundle branch reentry ${ }^{124}$

1. Generally occurs in patients with diffuse conduction system disease

2. Role of different maneuvers, comparison of $\mathrm{HH}$ and $\mathrm{VV}$ intervals, postpacing interval

3. Catheter ablation of post-infarction $\mathrm{VT}^{125,126}$

A. Most appropriate as palliative therapy for frequent VT in patients with implantable defibrillators

B. Potential role for prevention of ICD discharges

C. Mechanism is reentry using surviving myocytes within scar tissue

D. Mapping: Entrainment if hemodynamically tolerated, pace-mapping for non-tolerated VTs, identification of isolated potentials 
4. Catheter ablation of frequent PVCs in patients with cardiomyopathy ${ }^{127}$ and PVCinduced ventricular fibrillation (VF) or polymorphic $\mathrm{VT}^{128}$

A. Recognize the relation of frequent PVCs in cardiomyopathy that is reversible with radiofrequency ablation. Ventricular fibrillation or polymorphic VT triggered by PVCs can be controlled by ablation of the initiating PVCs.

\section{Pacemakers (include indications)}

The principles and practice of cardiac pacing are core competencies for a cardiac electrophysiologist. ${ }^{129}$ Fellows should fully understand the indications for temporary and permanent pacing, their limitations, and how to combine them with other therapies. Fellows should be technically proficient in placing, programming and troubleshooting such devices. Knowledge of the biophysics of pacing, the bioengineering of pacemakers and how they may be influenced by external devices and biophysical sources is also important.

A. Pathophysiology of various bradyarrhythmias, their etiology and natural history 130,131

B. Effects of pharmacologic, ablation and radiation therapy on sinus nodal, AV nodal and His-Purkinje system function

C. Physiologic pacing, including pacing modes, ${ }^{132}$ effects of pacing on electrical and mechanical function of cardiac chambers, prevention of unnecessary RV pacing, ${ }_{133}$ His-bundle, ${ }^{134}$ Bachmann's bundle and septal/ventricular outflow tract pacing, concepts of CRT-P. ${ }^{130}$ Data on comparative atrial pacing locations. ${ }^{135}$

D. Understanding pacing system technology

a. Leads (including electrode configuration, fixation, insulation, conductors, and connectors)

b. Pulse generators (including batteries, circuitry, sensors, and function, including monitoring)

c. Biophysics of pacing, including strength duration curves

d. Electronics; sensing/stimulation/defibrillation

i. Basic quantities (ampere, charge, coulomb, ohm, volt, hertz)

ii. Derived quantities (resistance, capacitance, battery capacity) and Ohm's Law

e. Knowledge of timing cycles, blanking and refractory periods

f. Sensors (motion/activity and minute ventilation)

g. Mode switching algorithms

h. Emerging pacing energy sources, devices, diagnostics and other functionality

E. Temporary pacing ${ }^{130}$ 
1. Indications

2. Techniques

F. Permanent pacemaker indications $s^{130}$

G. Permanent pacemaker implantation (training program should provide sufficient experience and resources to enable fellows to perform pacemaker implantation, troubleshooting and interrogation)

1. Pre procedure planning, including decisions on conscious sedation, periprocedural anticoagulation ${ }^{136}$ and antimicrobial agents ${ }^{137}$

2. Anatomic considerations, including normal and abnormal cardiac and great vessel variations, and selection of subcutaneous or subpectoral pocket locations

3. Venous access approaches including cephalic, subclavian or axillary veins, and unusual situations requiring the internal jugular or iliac veins

4. Techniques to deal with limited venous access

- Upsizing sheaths in cases of venous stenosis, consideration of balloon angioplasty or lead explantation to enable lead delivery

- Tunneling

- Using existing leads to provide access into central veins ${ }^{138}$

5. Interpreting electrograms from pacing system analyzers ${ }^{139}$

6. Evaluation of sensing, pacing parameters and impedances

7. Radiation safety

8. Knowledge of alternatives to transvenous lead placement in congenital heart disease, including epicardial and transatrial approaches

9. Intra-operative complication recognition and management

H. Radiology

1. Fluoroscopic views and lead locations

2. Post operative $X$-ray evaluation and identification of complications

I. Immediate post-procedure care; recognition and management of complications

J. Permanent pacemaker follow-up and troubleshooting 140

1. Comprehensive knowledge of specific device and lead parameters, and which are most applicable to specific clinical scenarios

2. 12-Lead ECG recognition of device function, malfunction and pacing site 
3. Experience of various follow-up approaches, including clinic-based interrogation, familiarity with transtelephonic follow-up, and remote monitoring data from various manufacturers ${ }^{141}$

4. Monitoring and application of adaptive algorithms such as auto capture, minimization of ventricular pacing, selection of AV intervals

5. Optimization of AV and VV timing by use of device-based algorithms and modalities such as echocardiography

6. Determination of when to replace a pacemaker with another cardiac implanted electronic device

K. Lead extraction ${ }^{142}$

1. Indication

2. Techniques and tools

i. Superior approach

ii. Femoral approach

iii. Powered and non-powered sheaths

iv. Snares

3. Complications

L. Device-device, device-drug, device-environmental (electromagnetic) interactions

M. Management in patients with terminal illness ${ }^{143}$

\section{ICD and CRT}

A training program in clinical cardiac electrophysiology should include sufficient technical and clinical instruction in advanced device management to allow the fellow to provide highly competent clinical assessment, patient selection, device implantation, and follow-up of eligible patients. This applies to single and dual chamber ICDs, and CRT-D and CRT-P systems. This includes the direct management of the patient with respect to cardiac arrhythmias, the overall management of the patient including heart failure and the implanted system management with respect to performance.

A. Technologic principles

1. Basic design of leads, generators and programmers ${ }^{144}$

i. Shock coils and shock vectors

ii. Integrated vs dedicated bipolar design

2. Understanding of the function of the ICD/CRT system

3. Defibrillation waveforms (tilt and pulse width)

4. Programming principles

5. Detection and discrimination algorithms/enhancements 
6. Diagnostic storage capabilities

7. Physiologic monitor parameters

B. Indications for the ICD/CRT system and appropriate integration of results of prospective trials into clinical decision-making ${ }^{145-148}$

C. Guidelines for implantation of ICD/CRT systems: American College of Cardiology/American Heart Association (ACC/AHA)/(HRS) ${ }^{147,148}$

D. Implantation techniques and testing of ICD/CRT system function at implantation ${ }^{130}$

a. Intra-operative defibrillation testing (DFT)

b. Defibrillation probability curve

E. Indication and implantation of coronary sinus leads to enable biventricular pacing ${ }^{149-152}$

F. Drug-ICD interaction, including drug management at the time of implantation

G. Implant procedure complications, including subsequent wound management

H. Follow-up and troubleshooting, including awareness of device and lead performance measures and advisories/recalls

I. Recommendations for driving for the patient ${ }^{153,154}$

J. Cost-effectiveness of the ICD/CRT system

K. Quality of life and psychosocial impact of the ICD/CRT system

\section{Special conditions}

\section{1: Syncope}

The evaluation and management of patients with unexplained syncope is an important component of electrophysiology fellowship training. The fellow must understand the guidelines for hospitalization, ${ }^{155,156}$ develop a strategy to identify a cause of syncope, ${ }^{155-159}$ and effectively risk stratify patients. ${ }^{155,157,160-162}$ Prolonged electrocardiographic (ECG) monitoring is an important diagnostic tool in some patients. ${ }^{159}$ Patients with structural heart disease are increasingly being treated with an implantable cardioverterdefibrillator (ICD); however, mortality remains high in these patients. ${ }^{155,161,162}$

A. Epidemiology and prognosis $155,157,160-162$

B. Value of history, physical examination, electrocardiogram, and evaluation for underlying structural heart disease ${ }^{155}$

C. Utility of syncope units

D. Classifications ${ }^{155,162}$

1. Neurally mediated syncope

2. Disorders of orthostatic hypotension and orthostatic intolerance 
3. Cardiac syncope

- Bradyarrhythmias

$$
\begin{array}{ll}
-\quad & \text { Sinus bradycardia } \\
\text { - } & \text { Atrioventricular block }
\end{array}
$$

- Tachyarrhythmias

- Supraventricular

- Ventricular

E. Value of diagnostic tests, including tilt table tests, short and long-term ECG monitoring, and electrophysiologic testing ${ }^{155,159,162}$

F. Treatment ${ }^{130,155}$

1. Lifestyle measures

2. Physical counter-pressure maneuvers and tilt training

3. Pharmacologic interventions

4. Permanent pacemakers

5. ICDs

G. Special conditions

1. Arrhythmogenic right ventricular cardiomyopathy 163

2. Brugada syndrome

3. Congenital long QT syndrome ${ }^{164,165}$

4. Hypertrophic cardiomyopathy 166

\section{2: Sudden cardiac death}

It is important for electrophysiology fellows to recognize the magnitude and different mechanisms that underlie sudden cardiac death (SCD). Fellows should be cognizant of the different precipitants of arrhythmias; comprehend evidence-based strategies for managing patients who are survivors of SCD; understand the pharmacological and nonpharmacological approaches of managing patients at risk for SCD; and grasp the different risk stratification strategies to predict and prevent SCD. Fellows should be up to date with all the completed clinical trials in this area while being aware of the most important studies nearing completion.

A. Definition and magnitude of problem

1. Incidence ${ }^{167,168}$

2. Epidemiology 169

3. Risk factors 169

B. Mechanisms of sudden death ${ }^{147,170}$ 
1. Arrhythmic mechanisms

- Ventricular tachycardia/ventricular fibrillation

- $\quad$ Torsades de pointes ${ }^{171}$

- $\quad$ Bradyarrhythmias

2. Channelopathies

- $\quad$ Long QT syndromes ${ }^{172,173}$

- $\quad$ Short QT syndromes

- $\quad$ Brugada syndrome ${ }^{174}$

3. Other genetic defects ${ }^{175}$

-Arrhythmogenic right ventricular dysplasia ${ }^{30,163}$

-Hypertrophic cardiomyopathy 176

-Catecholaminergic polymorphic ventricular tachycardia

-Early repolarization syndrome ${ }^{40}$

4. Metabolic, infiltrative and inflammatory conditions ${ }^{177}$

- $\quad$ Myocarditis

- $\quad$ Amyloidosis

- $\quad$ Sarcoidosis

- $\quad$ Hemochromatosis, Fabry’s disease, etc.

C. Precipitants

1. Myocardial ischemia

2. Electrolyte abnormalities

3. Autonomic nervous system ${ }^{178}$

4. Congestive heart failure

5. Drug-induced proarrhythmia (e.g., long QT, digitalis toxicity, etc.) ${ }^{171}$

D. Management

1. ACLS guidelines ${ }^{179,180}$

2. Evaluation and therapy of structural heart disease and ischemia, including echocardiography, exercise testing, cardiac catheterizations, CT and MRI

3. Role of electrophysiological testing ${ }^{181}$

4. Role of pharmacological therapy

5. Role of ICD therapy

6. Role of catheter ablation and surgical therapies 
7. Role of ancillary therapies (i.e., neurohormonal modulation, anti-ischemia, autonomic blockade etc. $)^{178}$

E. Risk stratification

1. Role, sensitivity and specificity of programmed ventricular stimulation in patients with reduced left ventricular ejection fraction with and without coronary artery disease ${ }^{181,182}$

2. Role, sensitivity and specificity of heart rate variability, signal-averaged electrocardiography, $\mathrm{T}$ wave alternans, heart rate turbulence, QT interval dispersion to prognosticate risk in certain subsets of patients ${ }^{32}$

3. Specific issues in athletes, including patient evaluation and limitation of activities $^{183,184}$

4. Provocative maneuvers in patients with possible genetic ion channel abnormalities

5. Specific considerations in patients with hypertrophic cardiomyopathy 176,185

F. Completed clinical trials

1. MADIT I and MADIT-II ${ }^{146,186}$

2. $\mathrm{SCD}-\mathrm{HeFT}^{145}$

3. DEFINITE ${ }^{187}$

4. MUSTT $^{188}$

5. Antiarrhythmics Versus Implantable Defibrillators (AVID) trial, ${ }^{189}$ Cardiac Arrest Study Hamburg (CASH) ${ }^{190}$ and Canadian Implantable Defibrillator Study (CIDS) ${ }^{191}$

6. MASTER Trial

\section{Insight on ABIM}

When a constituent body of the American Board of Medical Specialties (ABMS), such as the American Board of Internal Medicine, decides that a specialty area has matured sufficiently, the Board establishes an examination in that field and prescribes the body of knowledge that will be covered by the examination. In a somewhat analogous fashion, the Accreditation Council for Graduate Medical Education (ACGME) then directs one of its Residency Review Committees (RRC) to establish the standards to determine whether a given hospital or other learning center can provide the necessary resources to provide the prescribed education. The ACGME provides a learning philosophy (presently the "six competencies") and accreditation of teaching sites is based on whether such sites, including staff, faculty, and trainees, are performing satisfactorily with respect to the six competencies. The ACGME makes these determinations based on standardized self-study forms (Program Information Forms) from each site, and an exhaustive site visit that is carried out at intervals that depend largely on the overall track record of a given site, and 
how well the site has responded to citations from previous reviews. All of this takes a lively interaction among many interested parties, including professional societies such as the Heart Rhythm Society and the American College of Cardiology, the "House of Medicine" (American Medical Association), hospitals (American Hospital Association), and primary specialty groups (e.g., American College of Physicians-ACP). All of these are advisory.

The ABIM is definitive when it comes to the qualifications of an individual to sit for the boards. The ACGME through its RRCs is definitive when it comes to certifying a site as capable of providing the necessary learning experience. Many cardiology fellows and CCEP fellows believe that the ACC's Core Cardiology Training (COCATS) criteria are definitive; although influential, they are not definitive. The Residency Review Committee's criteria are definitive and differ somewhat from both the current ABIM and COCATS criteria.

At the time of first approval, the knowledge and experience base needed to sit for the board exams are determined by the ABIM. Thereafter, it is an iterative process. At the present time, the ABIM is funneling its energies into changing over from the concept of a test every 10 years to an ongoing maintenance of certification process that emphasizes lifelong learning. Thus, the RRC's proposed program requirements for clinical cardiac electrophysiology have more detailed and stricter electrophysiology procedure requirements than those of the ABIM. However, this does not pose a problem because one must be a graduate of an ACGME-approved program to sit for the ABIM boards.

ABIM PROCESS: The main component is the educational philosophy of lifelong learning, which is part of the evolution from certification to recertification to maintenance of certification. For each of the areas for which there is a board examination or "added qualifications" exam, a committee of experts is convened. This committee also contains educational philosophers and psychometricians. Together, they develop an examination designed to test the relevant body of knowledge in as fair and scientific a method as possible. The physician experts are usually well known in their respective field and they bring with them information from their professional bodies, the literature, and their own experience.

The ACGME has RRCs for the broad specialties. For example, there is an RRC for internal medicine that certifies the training programs for the core internal medicine training programs, all the subspecialties (in this case cardiology) and all the "sub-subs," e.g., CCEP. The ACGME provides broad umbrella requirements that extend to all major specialties (Surgery, Pediatrics, Internal Medicine, etc.), and the respective RRCs use these broad guidelines to develop the specific and detailed guidelines for each training program. Thus, program directors in CCEP need to look at the "common program requirements" and the respective program requirements for Internal Medicine and Cardiology, as well as those for CCEP. The subspecialties do not exist in a vacuum, but must be in an overall milieu, which includes a core internal medicine program, and several specialties with close communication from the various program directors. For each program, the RRC determines many of the details, such as minimum faculty, procedure volumes, conferences, continuity clinic, etc. Again, following the ACGME philosophy, the RRCs are charged with ensuring that the programs and the learners are all imbued with the concept of the six competencies. Indeed, 
outcomes are judged largely by assessment of how well the six competencies have been achieved by the residents and fellows at the time of completion of their program.

Input through the RRCs comes from many sources. The RRC leads many patterns each year, with agendas that include evaluation of programs based on self-study and site visits and other meetings at which strategy, tactics, and updates are the primary items on the agenda. The internal medicine RRC is comprised of five generalists and two physicians from each of the specialties. At the present time, the author represents cardiology broadly and electrophysiology in particular. There is another nonelectrophysiology cardiologist on the committee. A subcommittee of the RRC establishes the program requirements for each of the subspecialties and sub-subs. Each RRC meeting is also attended by staff, some of whom are specifically assigned to the internal medicine RRC, and by others who represent the general ACGME. Further, there are ex official members, nonvoting, representing the ABIM, American Medical Association, and American College of Physicians.

Input for determination of requirements for internal medicine and all its subs and sub-subs is reported to a subcommittee of the RRC, which establishes proposed requirements. Input can come from any source, ranging from the literature to special advisory groups such as cocats, the ABIM, etc. The RRC is in the position of having authority over all internal medicine training programs in the United States. It, therefore, recognizes the variation that can exist; thus, some requirements may differ from those proposed by professional organizations. In some cases, promulgation of such "ideal" requirements would endanger the certification of a number of otherwise strong training programs. The reader of program requirements must also be aware of the RRC "coded language," in which "suggests" means "it would be a very good idea," "should" means "you really ought to do it or tell us why," and "must" means "just do it."

\section{SUMMARY}

The ABIM is definitive for the individual, and the ACGME/RRC is definitive for programs (Figure 1). There is some overlap in a Venn diagram fashion between the areas covered by these two definitive organizations. Other bodies, organizations, or ideas are advisory only.

\section{References}

1. Link MS, Antzelevitch C, Waldo AL, et al. Clinical cardiac electrophysiology fellowship teaching objectives for the new millennium. J Cardiovasc Electrophysiol. 2001; 12:1433-1443. [PubMed: 11798006]

2. Surawicz, B. Electrophysiologic basis of ECG and cardiac arrhythmias. Williams and Wilkins; Baltimore, MD: 1995.

3. Monfredi O, Dobrzynski H, Mondal T, Boyett MR, Morris GM. The anatomy and physiology of the sinoatrial node—a contemporary review. Pacing Clin Electrophysiol. 2010; 33:1392-1406. [PubMed: 20946278]

4. Kurian T, Ambrosi C, Hucker W, Fedorov VV, Efimov IR. Anatomy and electrophysiology of the human AV node. Pacing Clin Electrophysiol. 2010; 33:754-762. [PubMed: 20180918]

5. Lachman N, Syed FF, Habib A, et al. Correlative anatomy for the electrophysiologist, part II: cardiac ganglia, phrenic nerve, coronary venous system. J Cardiovasc Electrophysiol. 2011; 22:104-110. [PubMed: 20807274] 
6. Kushnir A, Marks AR. The ryanodine receptor in cardiac physiology and disease. Adv Pharmacol. 2010; 59:1-30. [PubMed: 20933197]

7. Priori SG, Barhanin J, Hauer RN, et al. Genetic and molecular basis of cardiac arrhythmias: impact on clinical management parts I and II. Circulation. 1999; 99:518-528. [PubMed: 9927398]

8. Beinart R, Ruskin J, Milan D. The genetics of conduction disease. Heart Fail Clin. 2010; 6:201-214. [PubMed: 20347788]

9. Campuzano O, Beltran-Alvarez P, Iglesias A, Scornik F, Perez G, Brugada R. Genetics and cardiac channelopathies. Genet Med. 2010; 12:260-267. [PubMed: 20386317]

10. Heist EK, Ruskin JN. Drug-induced arrhythmia. Circulation. 2010; 122:1426-1435. [PubMed: 20921449]

11. Hurst JW. Naming of the waves in the ECG, with a brief account of their genesis. Circulation. 1998; 98:1937-1942. [PubMed: 9799216]

12. Antzelevitch C. Cellular basis for the repolarization waves of the ECG. Ann N Y Acad Sci. 2006; 1080:268-281. [PubMed: 17132789]

13. Roden DM, Balser JR, George AL Jr, Anderson ME. Cardiac ion channels. Annu Rev Physiol. 2002; 64:431-475. [PubMed: 11826275]

14. Watanabe H, Murakami M, Ohba T, Takahashi Y, Ito H. TRP channel and cardiovascular disease. Pharmacol Ther. 2008; 118:337-351. [PubMed: 18508125]

15. Priori SG, Napolitano C, Tiso N, et al. Mutations in the cardiac ryanodine receptor gene (hRyR2) underlie catecholaminergic polymorphic ventricular tachycardia. Circulation. 2001; 103:196-200. [PubMed: 11208676]

16. Sheikh F, Ross RS, Chen J. Cell-cell connection to cardiac disease. Trends Cardiovasc Med. 2009; 19:182-190. [PubMed: 20211433]

17. Anderson ME, Higgins LS, Schulman H. Disease mechanisms and emerging therapies: protein kinases and their inhibitors in myocardial disease. Nat Clin Pract Cardiovasc Med. 2006; 3:437445. [PubMed: 16874356]

18. Nass RD, Aiba T, Tomaselli GF, Akar FG. Mechanisms of disease: ion channel remodeling in the failing ventricle. Nat Clin Pract Cardiovasc Med. 2008; 5:196-207. [PubMed: 18317475]

19. Anderson ME, Al-Khatib SM, Roden DM, Califf RM. Cardiac repolarization: current knowledge, critical gaps, and new approaches to drug development and patient management. Am Heart J. 2002; 144:769-781. [PubMed: 12422144]

20. Knollmann BC, Roden DM. A genetic framework for improving arrhythmia therapy. Nature. 2008; 451:929-936. [PubMed: 18288182]

21. Ackerman MJ. Cardiac channelopathies: it's in the genes. Nat Med. 2004; 10:463-464. [PubMed: 15122246]

22. Tester, DJ.; Ackerman, MJ. Heart Disease. 9th ed.. Elsevier; Philadelphia: 2010. Genetics of cardiac arrhythmias; p. 81-90.Braunwald

23. Alsheikh-Ali AA, Madias C, Supran S, Link MS. Marked variability in susceptibility to ventricular fibrillation in an experimental commotio cordis model. Circulation. 2010; 122:2499-2504. [PubMed: 21126977]

24. Lehnart SE, Ackerman MJ, Benson DW Jr, et al. Inherited arrhythmias: a National Heart, Lung, and Blood Institute and Office of Rare Diseases workshop consensus report about the diagnosis, phenotyping, molecular mechanisms, and therapeutic approaches for primary cardiomyopathies of gene mutations affecting ion channel function. Circulation. 2007; 116:2325-2345. [PubMed: 17998470]

25. Priori SG, Barhanin J, Hauer RN, et al. Genetic and molecular basis of cardiac arrhythmias: impact on clinical management part III. Circulation. 1999; 99:674-681. [PubMed: 9950666]

26. Tester DJ, Ackerman MJ. Genetic testing for potentially lethal, highly treatable inherited cardiomyopathies/channelopathies in clinical practice. Circulation. 2011; 123:1021-1037. [PubMed: 21382904]

27. Bai R, Napolitano C, Bloise R, Monteforte N, Priori SG. Yield of genetic screening in inherited cardiac channelopathies: how to prioritize access to genetic testing. Circ Arrhythm Electrophysiol. 2009; 2:6-15. [PubMed: 19808439] 
28. Kapa S, Tester DJ, Salisbury BA, et al. Genetic testing for long-QT syndrome: distinguishing pathogenic mutations from benign variants. Circulation. 2009; 120:1752-1760. [PubMed: 19841300]

29. Kadish AH, Buxton AE, Kennedy HL, et al. ACC/AHA clinical competence statement on electrocardiography and ambulatory electrocardiography: a report of the ACC/AHA/ACP-ASIM task force on clinical competence (ACC/AHA Committee to develop a clinical competence statement on electrocardiography and ambulatory electrocardiography) endorsed by the International Society for Holter and noninvasive electrocardiology. Circulation. 2001; 104:31693178. [PubMed: 11748119]

30. Marcus FI, McKenna WJ, Sherrill D, et al. Diagnosis of arrhythmogenic right ventricular cardiomyopathy/dysplasia: proposed modification of the task force criteria. Circulation. 2010; 121:1533-1541. [PubMed: 20172911]

31. Corrado D, Pelliccia A, Heidbuchel H, et al. Recommendations for interpretation of 12-lead electrocardiogram in the athlete. Eur Heart J. 2010; 31:243-259. [PubMed: 19933514]

32. Goldberger JJ, Cain ME, Hohnloser SH, et al. American Heart Association/American College of Cardiology Foundation/Heart Rhythm Society scientific statement on noninvasive risk stratification techniques for identifying patients at risk for sudden cardiac death: a scientific statement from the American Heart Association Council on Clinical Cardiology Committee on Electrocardiography and Arrhythmias and Council on Epidemiology and Prevention. Circulation. 2008; 118:1497-1518. [PubMed: 18833586]

33. Breithardt G, Cain ME, el-Sherif N, et al. Standards for analysis of ventricular late potentials using high-resolution or signal-averaged electrocardiography. A statement by a Task Force Committee of the European Society of Cardiology, the American Heart Association, and the American College of Cardiology. Circulation. 1991; 83:1481-1488. [PubMed: 2013173]

34. Bauer A, Malik M, Schmidt G, et al. Heart rate turbulence: standards of measurement, physiological interpretation, and clinical use: International Soci-ety for Holter and Noninvasive Electrophysiology Consensus. J Am Coll Cardiol. 2008; 52:1353-1365. [PubMed: 18940523]

35. Morady F, Oral H, Chugh A. Diagnosis and ablation of atypical atrial tachycardia and flutter complicating atrial fibrillation ablation. Heart Rhythm. 2009; 6:S29-S32. [PubMed: 19501552]

36. Yamada T, McElderry HT, Okada T, et al. Idiopathic left ventricular arrhythmias originating adjacent to the left aortic sinus of valsalva: electrophysiological rationale for the surface electrocardiogram. J Cardiovasc Electrophysiol. 2010; 21:170-176. [PubMed: 19804552]

37. Valles E, Bazan V, Marchlinski FE. ECG criteria to identify epicardial ventricular tachycardia in nonischemic cardiomyopathy. Circ Arrhythm Electrophysiol. 2010; 3:63-71. [PubMed: 20008307]

38. Riley MP, Marchlinski FE. ECG clues for diagnosing ventricular tachycardia mechanism. J Cardiovasc Electrophysiol. 2008; 19:224-229. [PubMed: 17971133]

39. Zhang L, Timothy KW, Vincent GM, et al. Spectrum of ST-T-wave patterns and repolarization parameters in congenital long-QT syndrome: ECG findings identify genotypes. Circulation. 2000; 102:2849-2855. [PubMed: 11104743]

40. Haissaguerre M, Derval N, Sacher F, et al. Sudden cardiac arrest associated with early repolarization. N Engl J Med. 2008; 358:2016-2023. [PubMed: 18463377]

41. Madias C, Maron BJ, Weinstock J, Estes NA 3rd, Link MS. Commotio cordis-sudden cardiac death with chest wall impact. J Cardiovasc Electrophysiol. 2007; 18:115-122. [PubMed: 17229310]

42. Maron BJ, Estes NA 3rd. Commotio cordis. N Engl J Med. 2010; 362:917-927. [PubMed: 20220186]

43. Gepstein L, Hayam G, Ben-Haim SA. A novel method for nonfluoroscopic catheter-based electroanatomical mapping of the heart. In vitro and in vivo accuracy results. Circulation. 1997; 95:1611-1622. [PubMed: 9118532]

44. Mandel W, Hayakawa H, Danzig R, Marcus HS. Evaluation of sino-atrial node function in man by overdrive suppression. Circulation. 1971; 44:59-66. [PubMed: 5561417] 
45. Reddy CP, Damato AN, Akhtar M, et al. Time dependent changes in the functional properties of the atrioventricular conduction system in man. Circulation. 1975; 52:1012-1022. [PubMed: 1182946]

46. Scheinman MM, Peters RW, Suave MJ, et al. Value of the H-Q interval in patients with bundle branch block and the role of prophylactic permanent pacing. Am J Cardiol. 1982; 50:1316-1322. [PubMed: 7148708]

47. Knight BP, Ebinger M, Oral H, et al. Diagnostic value of tachycardia features and pacing maneuvers during paroxysmal supraventricular tachycardia. J Am Coll Cardiol. 2000; 36:574-582. [PubMed: 10933374]

48. Hummel JD, Strickberger SA, Daoud E, et al. Results and efficiency of programmed ventricular stimulation with four extrastimuli compared with one, two, and three extrastimuli. Circulation. 1994; 90:2827-2832. [PubMed: 7994827]

49. Stevenson WG, Friedman PL, Sager PT, et al. Exploring postinfarction reentrant ventricular tachycardia with entrainment mapping. J Am Coll Cardiol. 1997; 29:1180-1189. [PubMed: 9137211]

50. Waldo AL, Henthorn RW, Plumb VJ, MacLean WA. Demonstration of the mechanism of transient entrainment and interruption of ventricular tachycardia with rapid atrial pacing. J Am Coll Cardiol. 1984; 3:422-430. [PubMed: 6693629]

51. Henthorn RW, Okumura K, Olshansky B, Plumb VJ, Hess PG, Waldo AL. A fourth criterion for transient entrainment: the electrogram equivalent of progressive fusion. Circulation. 1988; 77:1003-1012. [PubMed: 3359582]

52. Hirshfeld JW Jr, Balter S, Brinker JA, et al. ACCF/AHA/HRS/SCAI clinical competence statement on physician knowledge to optimize patient safety and image quality in fluoroscopically guided invasive cardiovascular procedures: a report of the American College of Cardiology Foundation/ American Heart Association/American College of Physicians Task Force on Clinical Competence and Training. Circulation. 2005; 111:511-532. [PubMed: 15687141]

53. Haines D. Biophysics of ablation: application to technology. J Cardiovasc Electrophysiol. 2004; 15:S2-S11. [PubMed: 15482456]

54. Kowey PR, Marinchak RA, Rials SJ, Bharucha DB. Classification and pharmacology of antiarrhythmic drugs. Am Heart J. 2000; 140:12-20. [PubMed: 10874257]

55. Darbar D, Roden DM. Pharmacogenetics of antiarrhythmic therapy. Expert Opin Pharmacother. 2006; 7:1583-1590. [PubMed: 16872261]

56. Ehrlich JR, Nattel S. Novel approaches for pharmacological management of atrial fibrillation. Drugs. 2009; 69:757-774. [PubMed: 19441867]

57. Patel C, Yan GX, Kowey PR. Dronedarone. Circulation. 2009; 120:636-644. [PubMed: 19687370]

58. Everett, THt; Lee, KW.; Wilson, EE.; Guerra, JM.; Varosy, PD.; Olgin, JE. Safety profiles and lesion size of different radiofrequency ablation technologies: a comparison of large tip, open and closed irrigation catheters. J Cardiovasc Electrophysiol. 2009; 20:325-335. [PubMed: 18803562]

59. Hogh Petersen H, Chen X, Pietersen A, Svendsen JH, Haunso S. Lesion dimensions during temperature-controlled radiofrequency catheter ablation of left ventricular porcine myocardium: impact of ablation site, electrode size, and convective cooling. Circulation. 1999; 99:319-325. [PubMed: 9892601]

60. Seiler J, Roberts-Thomson KC, Raymond JM, Vest J, Delacretaz E, Stevenson WG. Steam pops during irrigated radiofrequency ablation: feasibility of impedance monitoring for prevention. Heart Rhythm. 2008; 5:1411-1416. [PubMed: 18929327]

61. Feld GK, Daubert JP, Weiss R, Miles WM, Pelkey W. Acute and long-term efficacy and safety of catheter cryoablation of the cavotricuspid isthmus for treatment of type 1 atrial flutter. Heart Rhythm. 2008; 5:1009-1014. [PubMed: 18598956]

62. Haines DE, Watson DD, Verow AF. Electrode radius predicts lesion radius during radiofrequency energy heating. Validation of a proposed thermodynamic model. Circ Res. 1990; 67:124-129. [PubMed: 2364487]

63. Asirvatham SJ, Bruce CJ, Friedman PA. Advances in imaging for cardiac electrophysiology. Coron Artery Dis. 2003; 14:3-13. [PubMed: 12629322] 
64. Hemminger EJ, Girsky MJ, Budoff MJ. Applications of computed tomography in clinical cardiac electrophysiology. J Cardiovasc Comput Tomogr. 2007; 1:131-142. [PubMed: 19083897]

65. Banchs JE, Patel P, Naccarelli GV, Gonzalez MD. Intracardiac echocardiography in complex cardiac catheter ablation procedures. J Interv Card Electrophysiol. 2010; 28:167-184. [PubMed: 20480388]

66. Ferguson JD, Helms A, Mangrum JM, et al. Catheter ablation of atrial fibrillation without fluoroscopy using intracardiac echocardiography and electroanatomic mapping. Circ Arrhythm Electrophysiol. 2009; 2:611-619. [PubMed: 20009075]

67. Singh SM, Heist EK, Donaldson DM, et al. Image integration using intracardiac ultrasound to guide catheter ablation of atrial fibrillation. Heart Rhythm. 2008; 5:1548-1555. [PubMed: 18984531]

68. Malchano ZJ, Neuzil P, Cury RC, et al. Integration of cardiac CT/MR imaging with threedimensional electroanatomical mapping to guide catheter manipulation in the left atrium: implications for catheter ablation of atrial fibrillation. J Cardiovasc Electrophysiol. 2006; 17:1221-1229. [PubMed: 17074008]

69. Bruder O, Wagner A, Jensen CJ, et al. Myocardial scar visualized by cardiovascular magnetic resonance imaging predicts major adverse events in patients with hypertrophic cardiomyopathy. $\mathrm{J}$ Am Coll Cardiol. 2010; 56:875-887. [PubMed: 20667520]

70. Fuster V, van der Zee S, Miller MA. Evolving anatomic, functional, and molecular imaging in the early detection and prognosis of hypertrophic cardiomyopathy. J Cardiovasc Transl Res. 2009; 2:398-406. [PubMed: 20559998]

71. Montant P, Chenot F, Goffinet C, et al. Detection and quantification of myocardial scars by contrast-enhanced 3D echocardiography. Circ Cardiovasc Imaging. 2010; 3:415-423. [PubMed: 20516483]

72. Cosio FG, Anderson RH, Kuck KH, et al. Living anatomy of the atrioventricular junctions. A guide to electrophysiologic mapping. A Consensus Statement from the Cardiac Nomenclature Study Group, Working Group of Arrhythmias, European Society of Cardiology, and the Task Force on Cardiac Nomenclature from NASPE. Circulation. 1999; 100:e31-e37. [PubMed: 10430823]

73. Lee KW, Badhwar N, Scheinman MM. Supraventricular tachycardia—part I. Curr Probl Cardiol. 2008; 33:467-546. [PubMed: 18707990]

74. Lee KW, Badhwar N, Scheinman MM. Supraventricular tachycardia—part II: history, presentation, mechanism, and treatment. Curr Probl Cardiol. 2008; 33:557-622. [PubMed: 18772055]

75. Nakagawa H, Jackman WM. Catheter ablation of paroxysmal supraventricular tachycardia. Circulation. 2007; 116:2465-2478. [PubMed: 18025404]

76. Jackman WM, Beckman KJ, McClelland JH, et al. Treatment of supraventricular tachycardia due to atrioventricular nodal reentry, by radiofrequency catheter ablation of slow-pathway conduction. N Engl J Med. 1992; 327:313-318. [PubMed: 1620170]

77. Calkins H, Sousa J, el-Atassi R, et al. Diagnosis and cure of the Wolff-Parkinson-White syndrome or paroxysmal supraventricular tachycardias during a single electrophysiologic test. N Engl J Med. 1991; 324:1612-1618. [PubMed: 2030717]

78. Jackman WM, Wang X, Friday KJ, et al. Catheter ablation of accessory atrioventricular pathways (Wolff-Parkinson-White syndrome) by radiofrequency current. N Engl J Med. 1991; 324:16051611. [PubMed: 2030716]

79. Tracy CM, Swartz JF, Fletcher RD, et al. Radiofrequency catheter ablation of ectopic atrial tachycardia using paced activation sequence mapping. J Am Coll Cardiol. 1993; 21:910-917. [PubMed: 8450159]

80. Nakagawa H, Shah N, Matsudaira K, et al. Characterization of reentrant circuit in macroreentrant right atrial tachycardia after surgical repair of congenital heart disease: isolated channels between scars allow "focal" ablation. Circulation. 2001; 103:699-709. [PubMed: 11156882]

81. Michaud GF, Tada H, Chough S, et al. Differentiation of atypical atrioventricular node re-entrant tachycardia from orthodromic reciprocating tachycardia using a septal accessory pathway by the response to ventricular pacing. J Am Coll Cardiol. 2001; 38:1163-1167. [PubMed: 11583898] 
82. Crawford TC, Mukerji S, Good E, et al. Utility of atrial and ventricular cycle length variability in determining the mechanism of paroxysmal supraventricular tachycardia. J Cardiovasc Electrophysiol. 2007; 18:698-703. [PubMed: 17537206]

83. Knight BP, Zivin A, Souza J, et al. A technique for the rapid diagnosis of atrial tachycardia in the electrophysiology laboratory. J Am Coll Cardiol. 1999; 33:775-781. [PubMed: 10080480]

84. Waldo AL. Mechanisms of atrial fibrillation. J Cardiovasc Electrophysiol. 2003; 14:S267-S274. [PubMed: 15005213]

85. Vaquero M, Calvo D, Jalife J. Cardiac fibrillation: from ion channels to rotors in the human heart. Heart Rhythm. 2008; 5:872-879. [PubMed: 18468960]

86. Calkins H, Brugada J, Packer DL, et al. HRS/EHRA/ECAS expert consensus statement on catheter and surgical ablation of atrial fibrillation: recommendations for personnel, policy, procedures and follow-up. A report of the Heart Rhythm Society (HRS) Task Force on catheter and surgical ablation of atrial fibrillation. Heart Rhythm. 2007; 4:816-861. [PubMed: 17556213]

87. Fuster V, Ryden LE, Cannom DS, et al. ACC/AHA/ESC 2006 Guidelines for the Management of Patients with Atrial Fibrillation: a report of the American College of Cardiology/American Heart Association Task Force on Practice Guidelines and the European Society of Cardiology Committee for Practice Guidelines (Writing Committee to Revise the 2001 Guidelines for the Management of Patients With Atrial Fibrillation): developed in collaboration with the European Heart Rhythm Association and the Heart Rhythm Society. Circulation. 2006; 114:e257-e354. [PubMed: 16908781]

88. Wann LS, Curtis AB, January CT, et al. 2011 ACCF/AHA/HRS focused update on the management of patients with atrial fibrillation (updating the 2006 guideline): a report of the American College of Cardiology Foundation/American Heart Association Task Force on Practice Guidelines. Circulation. 2011; 123:104-123. [PubMed: 21173346]

89. Connolly SJ, Pogue J, Hart RG, et al. Effect of clopidogrel added to aspirin in patients with atrial fibrillation. N Engl J Med. 2009; 360:2066-2078. [PubMed: 19336502]

90. Connolly S, Pogue J, Hart R, et al. Clopidogrel plus aspirin versus oral anticoagulation for atrial fibrillation in the Atrial fibrillation Clopidogrel Trial with Irbesartan for prevention of Vascular Events (ACTIVE W): a randomised controlled trial. Lancet. 2006; 367:1903-1912. [PubMed: 16765759]

91. Connolly SJ, Ezekowitz MD, Yusuf S, et al. Dabigatran versus warfarin in patients with atrial fibrillation. N Engl J Med. 2009; 361:1139-1151. [PubMed: 19717844]

92. Nagarakanti R, Ezekowitz MD, Oldgren J, et al. Dabigatran versus warfarin in patients with atrial fibrillation: an analysis of patients undergoing cardioversion. Circulation. 2011; 123:131-136. [PubMed: 21200007]

93. Wyse DG, Waldo AL, DiMarco JP, et al. A comparison of rate control and rhythm control in patients with atrial fibrillation. N Engl J Med. 2002; 347:1825-1833. [PubMed: 12466506]

94. Van Gelder IC, Hagens VE, Bosker HA, et al. A comparison of rate control and rhythm control in patients with recurrent persistent atrial fibrillation. N Engl J Med. 2002; 347:1834-1840. [PubMed: 12466507]

95. Roy D, Talajic M, Nattel S, et al. Rhythm control versus rate control for atrial fibrillation and heart failure. N Engl J Med. 2008; 358:2667-2677. [PubMed: 18565859]

96. Van Gelder IC, Groenveld HF, Crijns HJ, et al. Lenient versus strict rate control in patients with atrial fibrillation. N Engl J Med. 2010; 362:1363-1373. [PubMed: 20231232]

97. Camm AJ, Kirchhof P, Lip GY, et al. Guidelines for the management of atrial fibrillation: the Task Force for the Management of Atrial Fibrillation of the European Society of Cardiology (ESC). Eur Heart J. 2010; 31:2369-2429. [PubMed: 20802247]

98. Klein AL, Grimm RA, Murray RD, et al. Use of transesophageal echocardiography to guide cardioversion in patients with atrial fibrillation. N Engl J Med. 2001; 344:1411-1420. [PubMed: 11346805]

99. Haissaguerre M, Jais P, Shah DC, et al. Spontaneous initiation of atrial fibrillation by ectopic beats originating in the pulmonary veins. N Engl J Med. 1998; 339:659-666. [PubMed: 9725923]

100. Oral H, Pappone C, Chugh A, et al. Circumferential pulmonary-vein ablation for chronic atrial fibrillation. N Engl J Med. 2006; 354:934-941. [PubMed: 16510747] 
101. Khan MN, Jais P, Cummings J, et al. Pulmonary-vein isolation for atrial fibrillation in patients with heart failure. N Engl J Med. 2008; 359:1778-1785. [PubMed: 18946063]

102. Matsuo S, Lellouche N, Wright M, et al. Clinical predictors of termination and clinical outcome of catheter ablation for persistent atrial fibrillation. J Am Coll Cardiol. 2009; 54:788-795. [PubMed: 19695455]

103. Callans DJ. Apples and oranges: comparing antiarrhythmic drugs and catheter ablation for treatment of atrial fibrillation. Circulation. 2008; 118:2488-2490. [PubMed: 19064689]

104. Ouyang F, Tilz R, Chun J, et al. Long-term results of catheter ablation in paroxysmal atrial fibrillation: lessons from a 5-year follow-up. Circulation. 2010; 122:2368-2377. [PubMed: 21098450]

105. Weerasooriya R, Khairy P, Litalien J, et al. Catheter ablation for atrial fibrillation: are results maintained at 5 years of follow-up? J Am Coll Cardiol. 2011; 57:160-166. [PubMed: 21211687]

106. Nademanee K, McKenzie J, Kosar E, et al. A new approach for catheter ablation of atrial fibrillation: mapping of the electrophysiologic substrate. J Am Coll Cardiol. 2004; 43:20442053. [PubMed: 15172410]

107. Haissaguerre M, Sanders P, Hocini M, et al. Catheter ablation of long-lasting persistent atrial fibrillation: critical structures for termination. J Cardiovasc Electrophysiol. 2005; 16:1125-1137. [PubMed: 16302892]

108. Takahashi Y, O’Neill MD, Hocini M, et al. Characterization of electrograms associated with termination of chronic atrial fibrillation by catheter ablation. J Am Coll Cardiol. 2008; 51:10031010. [PubMed: 18325439]

109. Oral H, Chugh A, Yoshida K, et al. A randomized assessment of the incremental role of ablation of complex fractionated atrial electrograms after antral pulmonary vein isolation for long-lasting persistent atrial fibrillation. J Am Coll Cardiol. 2009; 53:782-789. [PubMed: 19245970]

110. Pappone C, Santinelli V, Manguso F, et al. Pulmonary vein denervation enhances long-term benefit after circumferential ablation for paroxysmal atrial fibrillation. Circulation. 2004; 109:327-334. [PubMed: 14707026]

111. Shah DC, Jais P, Haissaguerre M, et al. Three-dimensional mapping of the common atrial flutter circuit in the right atrium. Circulation. 1997; 96:3904-3912. [PubMed: 9403614]

112. Jais P, Shah DC, Haissaguerre M, et al. Mapping and ablation of left atrial flutters. Circulation. 2000; 101:2928-2934. [PubMed: 10869265]

113. Chugh A, Oral H, Good E, et al. Catheter ablation of atypical atrial flutter and atrial tachycardia within the coronary sinus after left atrial ablation for atrial fibrillation. J Am Coll Cardiol. 2005; 46:83-91. [PubMed: 15992640]

114. Corrado G, Sgalambro A, Mantero A, et al. Thromboembolic risk in atrial flutter. The FLASIEC (FLutter Atriale Societa Italiana di Ecografia Cardiovascolare) multicentre study. Eur Heart J. 2001; 22:1042-1051. [PubMed: 11428839]

115. Natale A, Newby KH, Pisano E, et al. Prospective randomized comparison of antiarrhythmic therapy versus first-line radiofrequency ablation in patients with atrial flutter. J Am Coll Cardiol. 2000; 35:1898-1904. [PubMed: 10841241]

116. Da Costa A, Thevenin J, Roche F, et al. Results from the Loire-Ardeche-Drome-Isere-Puy-deDome (LADIP) trial on atrial flutter, a multicentric prospective randomized study comparing amiodarone and radiofrequency ablation after the first episode of symptomatic atrial flutter. Circulation. 2006; 114:1676-1681. [PubMed: 17030680]

117. Nakagawa H, Lazzara R, Khastgir T, et al. Role of the tricuspid annulus and the eustachian valve/ ridge on atrial flutter. Relevance to catheter ablation of the septal isthmus and a new technique for rapid identification of ablation success. Circulation. 1996; 94:407-424. [PubMed: 8759083]

118. Poty H, Saoudi N, Abdel Aziz A, Nair M, Letac B. Radiofrequency catheter ablation of type 1 atrial flutter. Prediction of late success by electrophysiological criteria. Circulation. 1995; 92:1389-1392. [PubMed: 7664417]

119. Aliot EM, Stevenson WG, Almendral-Garrote JM, et al. EHRA/HRS Expert Consensus on Catheter Ablation of Ventricular Arrhythmias: developed in a partnership with the European Heart Rhythm Association (EHRA), a Registered Branch of the European Society of Cardiology (ESC), and the Heart Rhythm Society (HRS); in collaboration with the American College of 
Cardiology (ACC) and the American Heart Association (AHA). Heart Rhythm. 2009; 6:886-933. [PubMed: 19467519]

120. Good E, Desjardins B, Jongnarangsin K, et al. Ventricular arrhythmias originating from a papillary muscle in patients without prior infarction: a comparison with fascicular arrhythmias. Heart Rhythm. 2008; 5:1530-1537. [PubMed: 18984528]

121. Bogun F, Taj M, Ting M, et al. Spatial resolution of pace mapping of idiopathic ventricular tachycardia/ectopy originating in the right ventricular outflow tract. Heart Rhythm. 2008; 5:339 344. [PubMed: 18313589]

122. Marchlinski FE, Callans DJ, Gottlieb CD, Zado E. Linear ablation lesions for control of unmappable ventricular tachycardia in patients with ischemic and nonischemic cardiomyopathy. Circulation. 2000; 101:1288-1296. [PubMed: 10725289]

123. Bogun FM, Desjardins B, Good E, et al. Delayed-enhanced magnetic resonance imaging in nonischemic cardiomyopathy: utility for identifying the ventricular arrhythmia substrate. J Am Coll Cardiol. 2009; 53:1138-1145. [PubMed: 19324259]

124. Merino JL, Peinado R, Fernandez-Lozano I, et al. Bundle-branch reentry and the postpacing interval after entrainment by right ventricular apex stimulation: a new approach to elucidate the mechanism of wide-QRS-complex tachycardia with atrioventricular dissociation. Circulation. 2001; 103:1102-1108. [PubMed: 11222473]

125. Stevenson WG, Wilber DJ, Natale A, et al. Irrigated radiofrequency catheter ablation guided by electroanatomic mapping for recurrent ventricular tachycardia after myocardial infarction: the multicenter thermocool ventricular tachycardia ablation trial. Circulation. 2008; 118:2773-2782. [PubMed: 19064682]

126. Reddy VY, Reynolds MR, Neuzil P, et al. Prophylactic catheter ablation for the prevention of defibrillator therapy. N Engl J Med. 2007; 357:2657-2665. [PubMed: 18160685]

127. Bogun F, Crawford T, Reich S, et al. Radiofrequency ablation of frequent, idiopathic premature ventricular complexes: comparison with a control group without intervention. Heart Rhythm. 2007; 4:863-867. [PubMed: 17599667]

128. Haissaguerre M, Shoda M, Jais P, et al. Mapping and ablation of idiopathic ventricular fibrillation. Circulation. 2002; 106:962-967. [PubMed: 12186801]

129. Naccarelli GV, Conti JB, DiMarco JP, Tracy CM. Task force 6: training in specialized electrophysiology, cardiac pacing, and arrhythmia management endorsed by the Heart Rhythm Society. J Am Coll Cardiol. 2008; 51:374-380. [PubMed: 18206755]

130. Epstein AE, DiMarco JP, Ellenbogen KA, et al. ACC/AHA/HRS 2008 Guidelines for DeviceBased Therapy of Cardiac Rhythm Abnormalities: a report of the American College of Cardiology/American Heart Association Task Force on Practice Guidelines (Writing Committee to Revise the ACC/AHA/NASPE 2002 Guideline Update for Implantation of Cardiac Pacemakers and Antiarrhythmia Devices): developed in collaboration with the American Association for Thoracic Surgery and Society of Thoracic Surgeons. Circulation. 2008; 117:e350-e408. [PubMed: 18483207]

131. Cheng S, Keyes MJ, Larson MG, et al. Long-term outcomes in individuals with prolonged PR interval or first-degree atrioventricular block. JAMA. 2009; 301:2571-2577. [PubMed: 19549974]

132. Bernstein AD, Daubert JC, Fletcher RD, et al. The revised NASPE/BPEG generic code for antibradycardia, adaptive-rate, and multisite pacing. North American Society of Pacing and Electrophysiology/British Pacing and Electrophysiology Group. Pacing Clin Electrophysiol. 2002; 25:260-264. [PubMed: 11916002]

133. Sweeney MO, Bank AJ, Nsah E, et al. Minimizing ventricular pacing to reduce atrial fibrillation in sinus-node disease. N Engl J Med. 2007; 357:1000-1008. [PubMed: 17804844]

134. Lustgarten DL, Calame S, Crespo EM, Calame J, Lobel R, Spector PS. Electrical resynchronization induced by direct His-bundle pacing. Heart Rhythm. 2010; 7:15-21. [PubMed: 19914142]

135. Hermida JS, Kubala M, Lescure FX, et al. Atrial septal pacing to prevent atrial fibrillation in patients with sinus node dysfunction: results of a randomized controlled study. Am Heart J. 2004; 148:312-317. [PubMed: 15309002] 
136. Tompkins C, Cheng A, Dalal D, et al. Dual antiplatelet therapy and heparin "bridging" significantly increase the risk of bleeding complications after pacemaker or implantable cardioverter-defibrillator device implantation. J Am Coll Cardiol. 2010; 55:2376-2382. [PubMed: 20488310]

137. de Oliveira JC, Martinelli M, Nishioka SA, et al. Efficacy of antibiotic prophylaxis before the implantation of pacemakers and cardioverter-defibrillators: results of a large, prospective, randomized, double-blinded, placebo-controlled trial. Circ Arrhythm Electrophysiol. 2009; 2:2934. [PubMed: 19808441]

138. Bognolo DA, Vijayanagar R, Eckstein PF, Janss B. Method for re-introduction of permanent endocardial pacing electrode. Pacing Clin Electrophysiol. 1982; 5:546-547. [PubMed: 6180397]

139. Saxonhouse SJ, Conti JB, Curtis AB. Current of injury predicts adequate active lead fixation in permanent pacemaker/defibrillation leads. J Am Coll Cardiol. 2005; 45:412-417. [PubMed: 15680721]

140. Wilkoff BL, Auricchio A, Brugada J, et al. HRS/EHRA expert consensus on the monitoring of cardiovascular implantable electronic devices (CIEDs): description of techniques, indications, personnel, frequency and ethical considerations. Heart Rhythm. 2008; 5:907-925. [PubMed: 18551743]

141. Crossley GH, Chen J, Choucair W, et al. Clinical benefits of remote versus transtelephonic monitoring of implanted pacemakers. J Am Coll Cardiol. 2009; 54:2012-2019. [PubMed: 19926006]

142. Baddour LM, Epstein AE, Erickson CC, et al. Update on cardiovascular implantable electronic device infections and their management: a scientific statement from the American Heart Association. Circulation. 2010; 121:458-477. [PubMed: 20048212]

143. Lampert R, Hayes DL, Annas GJ, et al. HRS Expert Consensus Statement on the Management of Cardiovascular Implantable Electronic Devices (CIEDs) in patients nearing end of life or requesting withdrawal of therapy. Heart Rhythm. 2010; 7:1008-1026. [PubMed: 20471915]

144. Russo, AM.; Marchlinski, F. Engineering and construction of pacemaker and implantable cardioverter-defibrillator leads. In: Ellenbogen, K., editor. Clinical Cardiac Pacing, Defibrillation, and Resynchronization Therapy. Third Edition. WB Saunders; Philadelphia: 2007. p. 161-200.

145. Bardy GH, Lee KL, Mark DB, et al. Amiodarone or an implantable cardioverterdefibrillator for congestive heart failure. N Engl J Med. 2005; 352:225-237. [PubMed: 15659722]

146. Moss AJ, Zareba W, Hall WJ, et al. Prophylactic implantation of a defibrillator in patients with myocardial infarction and reduced ejection fraction. N Engl J Med. 2002; 346:877-883. [PubMed: 11907286]

147. Zipes DP, Camm AJ, Borggrefe M, et al. ACC/AHA/ESC 2006 Guidelines for Management of Patients With Ventricular Arrhythmias and the Prevention of Sudden Cardiac Death: a report of the American College of Cardiology/American Heart Association Task Force and the European Society of Cardiology Committee for Practice Guidelines (writing committee to develop Guidelines for Management of Patients With Ventricular Arrhythmias and the Prevention of Sudden Cardiac Death): developed in collaboration with the European Heart Rhythm Association and the Heart Rhythm Society. Circulation. 2006; 114:e385-e484. [PubMed: 16935995]

148. Dickstein K, Vardas PE, Auricchio A, et al. 2010 focused update of ESC Guidelines on device therapy in heart failure: an update of the 2008 ESC Guidelines for the diagnosis and treatment of acute and chronic heart failure and the 2007 ESC Guidelines for cardiac and resynchronization therapy. Developed with the special contribution of the Heart Failure Association and the European Heart Rhythm Association. Eur J Heart Fail. 2010; 12:1143-1153. [PubMed: 20965877]

149. Cleland JG, Daubert JC, Erdmann E, et al. The effect of cardiac resynchronization on morbidity and mortality in heart failure. N Engl J Med. 2005; 352:1539-1549. [PubMed: 15753115]

150. Tang AS, Wells GA, Talajic M, et al. Cardiac-resynchronization therapy for mild-to-moderate heart failure. N Engl J Med. 2010; 363:2385-2395. [PubMed: 21073365]

151. Moss AJ, Hall WJ, Cannom DS, et al. Cardiac-resynchronization therapy for the prevention of heart-failure events. N Engl J Med. 2009; 361:1329-1338. [PubMed: 19723701] 
152. Singh JP, Klein HU, Huang DT, et al. Left ventricular lead position and clinical outcome in the Multicenter Automatic Defibrillator Implantation Trial-Cardiac Resynchronization Therapy (MADIT-CRT) Trial. Circulation. 2011; 123:1159-1166. [PubMed: 21382893]

153. Epstein AE, Baessler CA, Curtis AB, et al. Addendum to "Personal and public safety issues related to arrhythmias that may affect consciousness: implications for regulation and physician recommendations: a medical/scientific statement from the American Heart Association and the North American Society of Pacing and Electrophysiology": public safety issues in patients with implantable defibrillators: a scientific statement from the American Heart Association and the Heart Rhythm Society. Circulation. 2007; 115:1170-1176. [PubMed: 17287391]

154. Epstein AE, Miles WM, Benditt DG, et al. Personal and public safety issues related to arrhythmias that may affect consciousness: implications for regulation and physician recommendations. A medical/scientific statement from the American Heart Association and the North American Society of Pacing and Electrophysiology. Circulation. 1996; 94:1147-1166. [PubMed: 8790068]

155. Moya A, Sutton R, Ammirati F, et al. Guidelines for the diagnosis and management of syncope (version 2009). Eur Heart J. 2009; 30:2631-2671. [PubMed: 19713422]

156. Benditt DG, Nguyen JT. Syncope: therapeutic approaches. J Am Coll Cardiol. 2009; 53:17411751. [PubMed: 19422980]

157. Soteriades ES, Evans JC, Larson MG, et al. Incidence and prognosis of syncope. N Engl J Med. 2002; 347:878-885. [PubMed: 12239256]

158. Grubb BP. Clinical practice. Neurocardiogenic syncope. N Engl J Med. 2005; 352:1004-1010. [PubMed: 15758011]

159. Brignole M, Vardas P, Hoffman E, et al. Indications for the use of diagnostic implantable and external ECG loop recorders. Europace. 2009; 11:671-687. [PubMed: 19401342]

160. Alshekhlee A, Shen WK, Mackall J, Chelimsky TC. Incidence and mortality rates of syncope in the United States. Am J Med. 2009; 122:181-188. [PubMed: 19100958]

161. Olshansky B, Poole JE, Johnson G, et al. Syncope predicts the outcome of cardiomyopathy patients: analysis of the SCD-HeFT study. J Am Coll Cardiol. 2008; 51:1277-1282. [PubMed: 18371559]

162. Costantino G, Perego F, Dipaola F, et al. Short- and long-term prognosis of syncope, risk factors, and role of hospital admission: results from the STePS (Short-Term Prognosis of Syncope) study. J Am Coll Cardiol. 2008; 51:276-283. [PubMed: 18206736]

163. Corrado D, Calkins H, Link MS, et al. Prophylactic implantable defibrillator in patients with arrhythmogenic right ventricular cardiomyopathy/dysplasia and no prior ventricular fibrillation or sustained ventricular tachycardia. Circulation. 2010; 122:1144-1152. [PubMed: 20823389]

164. Jons C, Moss AJ, Goldenberg I, et al. Risk of fatal arrhythmic events in long QT syndrome patients after syncope. J Am Coll Cardiol. 2010; 55:783-788. [PubMed: 20170817]

165. Liu JF, Jons C, Moss AJ, et al. Risk factors for recurrent syncope and subsequent fatal or nearfatal events in children and adolescents with long QT syndrome. J Am Coll Cardiol. 2011; 57:941-950. [PubMed: 21329841]

166. Spirito P, Autore C, Rapezzi C, et al. Syncope and risk of sudden death in hypertrophic cardiomyopathy. Circulation. 2009; 119:1703-1710. [PubMed: 19307481]

167. Myerburg RJ, Kessler KM, Castellanos A. Sudden cardiac death: epidemiology, transient risk, and intervention assessment. Ann Intern Med. 1993; 119:1187-1197. [PubMed: 8239250]

168. Fishman GI, Chugh SS, Dimarco JP, et al. Sudden cardiac death prediction and prevention: report from a National Heart, Lung, and Blood Institute and Heart Rhythm Society Workshop. Circulation. 2010; 122:2335-2348. [PubMed: 21147730]

169. Chugh SS, Reinier K, Teodorescu C, et al. Epidemiology of sudden cardiac death: clinical and research implications. Prog Cardiovasc Dis. 2008; 51:213-228. [PubMed: 19026856]

170. Rubart M, Zipes DP. Mechanisms of sudden cardiac death. J Clin Invest. 2005; 115:2305-2315. [PubMed: 16138184]

171. Roden DM. Drug-induced prolongation of the QT interval. N Engl J Med. 2004; 350:1013-1022. [PubMed: 14999113] 
172. Goldenberg I, Moss AJ, Peterson DR, et al. Risk factors for aborted cardiac arrest and sudden cardiac death in children with the congenital long-QT syndrome. Circulation. 2008; 117:21842191. [PubMed: 18427136]

173. Kass RS, Moss AJ. Long QT syndrome: novel insights into the mechanisms of cardiac arrhythmias. J Clin Invest. 2003; 112:810-815. [PubMed: 12975462]

174. Brugada P, Brugada J. Right bundle branch block, persistent ST segment elevation and sudden cardiac death: a distinct clinical and electrocardiographic syndrome. J Am Coll Cardiol. 1992; 20:1391-1396. [PubMed: 1309182]

175. Priori SG, Napolitano C. Genetics of cardiac arrhythmias and sudden cardiac death. Ann N Y Acad Sci. 2004; 1015:96-110. [PubMed: 15201152]

176. Maron BJ, Spirito P, Shen WK, et al. Implantable cardioverter-defibrillators and prevention of sudden cardiac death in hypertrophic cardiomyopathy. JAMA. 2007; 298:405-412. [PubMed: 17652294]

177. Lubitz SA, Goldbarg SH, Mehta D. Sudden cardiac death in infiltrative cardiomyopathies: sarcoidosis, scleroderma, amyloidosis, hemachromatosis. Prog Cardiovasc Dis. 2008; 51:58-73. [PubMed: 18634918]

178. Zipes DP, Rubart M. Neural modulation of cardiac arrhythmias and sudden cardiac death. Heart Rhythm. 2006; 3:108-113. [PubMed: 16399065]

179. Neumar RW, Otto CW, Link MS, et al. Part 8: adult advanced cardiovascularlife support: 2010 American Heart Association Guidelines for Cardiopulmonary Resuscitation and Emergency Cardiovascular Care. Circulation. 2010; 122:S729-S767. [PubMed: 20956224]

180. Link MS, Atkins DL, Passman RS, et al. Part 6: electrical therapies: automated external defibrillators, defibrillation, cardioversion, and pacing: 2010 American Heart Association Guidelines for Cardiopulmonary Resuscitation and Emergency Cardiovascular Care. Circulation. 2010; 122:S706-S719. [PubMed: 20956222]

181. Schmitt C, Barthel P, Ndrepepa G, et al. Value of programmed ventricular stimulation for prophylactic internal cardioverter-defibrillator implantation in postinfarction patients preselected by noninvasive risk stratifiers. J Am Coll Cardiol. 2001; 37:1901-1907. [PubMed: 11401129]

182. Buxton AE, Hafley GE, Lehmann MH, et al. Prediction of sustained ventricular tachycardia inducible by programmed stimulation in patients with coronary artery disease. Utility of clinical variables. Circulation. 1999; 99:1843-1850. [PubMed: 10199881]

183. Maron BJ, Doerer JJ, Haas TS, Tierney DM, Mueller FO. Sudden deaths in young competitive athletes: analysis of 1866 deaths in the United States, 1980-2006. Circulation. 2009; 119:10851092. [PubMed: 19221222]

184. Link MS, Estes NA. Athletes and arrhythmias. J Cardiovasc Electrophysiol. 2010; 21:1184-1189. [PubMed: 20522153]

185. Miller MA, Gomes JA, Fuster V. Risk stratification of sudden cardiac death in hypertrophic cardiomyopathy. Nat Clin Pract Cardiovasc Med. 2007; 4:667-676. [PubMed: 18033231]

186. Moss AJ, Hall J, Cannom DS, et al. Improved survival with an implanted defibrillator in patients with coronary disease at high risk for ventricular arrhythmia. 1996; 335:1933-1940.

187. Kadish A, Dyer A, Daubert JP, et al. Prophylactic defibrillator implantation in patients with nonischemic dilated cardiomyopathy. N Engl J Med. 2004; 350:2151-2158. [PubMed: 15152060]

188. Buxton AE, Lee KL, Fisher JD, Josephson ME, Prystowsky EN, Hafley G. A Randomized study of the prevention of sudden death in patients with coronary artery disease. N Engl J Med. 1999; 341:1882-1890. [PubMed: 10601507]

189. AVID Investigators. A comparison of antiarrhythmic-drug therapy with implantable defibrillators in patients resuscitated from near-fatal ventricular arrhythmias. N Engl J Med. 1997; 337:15761583. [PubMed: 9411221]

190. Kuck KH, Cappato R, Siebels J, Ruppel R. Randomized comparison of antiarrhythmic drug therapy with implantable defibrillators in patients resuscitated from cardiac arrest: the Cardiac Arrest Study Hamburg (CASH). Circulation. 2000; 102:748-754. [PubMed: 10942742] 
191. Connolly SJ, Gent M, Roberts RS, et al. Canadian implantable defibrillator study (CIDS): a randomized trial of the implantable cardioverter defibrillator against amiodarone. Circulation. 2000; 101:1297-1302. [PubMed: 10725290] 


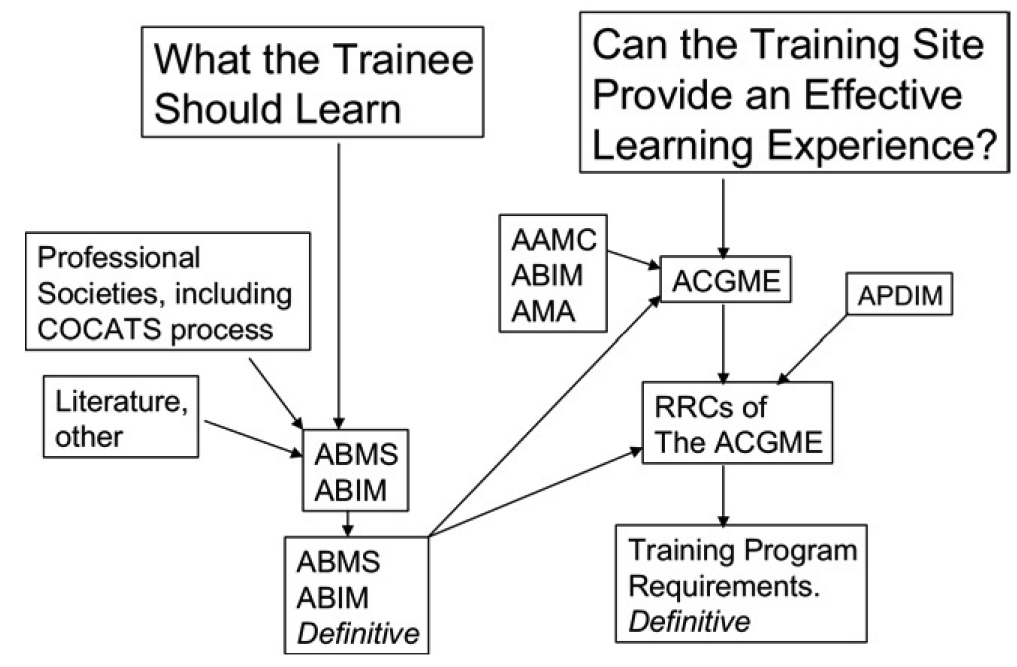

Figure 1.

Trainee learning experience. Interaction between the trainee, training site, and the various organizations such as COCATS (ACC's Core Cardiology Training), ABMS (American Board of Medical Specialties), ABIM (American Board of Internal Medicine), AAMC (Association of American Medical Colleges), AMA (American Medical Association), ACGME (Accreditation Council for Graduate Medical Education), APDIM (Association of Program Directors in Internal Medicine), RRC (Residency Review Committees). 